\title{
Update on options for treatment of metastatic castration-resistant prostate cancer
}

This article was published in the following Dove Press journal:

OncoTargets and Therapy

20 March 2010

Number of times this article has been viewed

\section{Prakash Vishnu \\ Winston W Tan}

Division of Hematology Oncology, Mayo Clinic, Jacksonville, FL, USA
Correspondence:Winston Tan Mayo Clinic, Division of Hematology Oncology, 4500 San Pablo Road, Jacksonville, FL, USA

$\mathrm{Tel}+\mathrm{I} 9049536153$

Fax + I 904953661 I

Email tan.winston@mayo.edu
Background: Prostate cancer is one of the most common cancers in men in US and European countries. Despite having a favorable prognosis, the incidence of incurable metastatic disease and mortality in the US is about 28,000 per year. Although hormone-based androgen deprivation therapies typically result in rapid responses, nearly all patients eventually develop progressive castration-resistant disease state. With readily available prostate-specific antigen (PSA) testing, most of these patients are asymptomatic and manifest progression simply as a rising PSA. In patients with castration-resistant prostate cancer (CRPC), the median survival is about 1-2 years, with improvements in survival seen mostly with docetaxel-based regimens. The purpose of this article is to review the recent developments in the treatment of advanced CRPC.

Recent findings: Since the two landmark trials (TAX-327 and Southwest Oncology Group 99-16) in CRPC, several newer cytotoxic drugs (epothilones, satraplatin), targeted agents (abiraterone, MDV3100) and vaccines have been tested in phase II and III setting with promising results.

Conclusions: The role of newer agents in the treatment of CRPC still needs to be validated by phase III trials, which are currently ongoing. Whilst the novel biomarkers, 'circulating tumor cells', have been shown to provide important prognostic information and are anticipated to be incorporated in future clinical decision-making, their exact utility and relevance calls for a larger prospective validation.

Keywords: castration-resistant prostate cancer, novel therapies, mechanisms of resistance, circulating tumor cells

\section{Introduction}

Prostate cancer is a highly prevalent and clinically heterogeneous disease. It is the most common cancer for men in the US with an estimated 192,280 new cases diagnosed in 2009. It also is the second leading cause of cancer deaths accounting for $9 \%$ of all cancer-related death in men. ${ }^{1}$ It has an exceptionally high incidence/mortality ratio compared to the other leading causes of cancer deaths. ${ }^{2}$ Rates of detection of prostate cancers vary widely across the world, with South and East Asia detecting less frequently than in Europe, and the United States. It is a highly curable disease if diagnosed at an early stage and 5-year relative survival rates based on Surveillance, Epidemiology, End Results (SEER) database's cancer statistics were $100.0 \%$ for both localized and regional disease, and $30.6 \%$ for distant disease. ${ }^{3}$

Despite having a favorable prognosis, there is a subgroup of prostate cancer patients who develop incurable metastatic disease (estimated to be around 28,000 each year in the US) and ultimately succumb to death as a result of advanced disease. 
Although androgen-deprivation therapies typically result in rapid responses, nearly all patients eventually develop progressive castration-resistant disease state. Several treatment options have been described for these patients with castration-resistant prostate cancer (CRPC) as listed in Table 1. However, most of the secondary hormone manipulation techniques despite achieving castrate levels of testosterone, provide temporary disease control only, and on average, after 12-18 months, the malignant cells develop resistance, with a reported median overall survival of approximately 30 months. ${ }^{4}$

Analysis of tumor specimens from patients with CRPC has shown several mechanisms adapted by cancer cells to reactivate the androgen receptor (AR) signaling at sub-physiological serum concentrations of androgens or even in the presence of AR antagonists. ${ }^{5}$ Several new drugs targeting these pathways are being developed and currently being tested in clinical trials.

In this article, we review recent developments in the treatment of advanced CRPC. We performed a systematic review of peer-reviewed publications identified through searches of MEDLINE/PubMed from 2003 to September 2009. We also included results of the relevant clinical trials presented at the annual oncology meetings (eg, Annual Meeting of American Society of Clinical Oncology [ASCO]). The ongoing phase II and phase III trials for first- and second-line chemotherapy for CRPC were searched from the US National Institute of Health's web resource, clinicaltrials.gov, which is a registry of clinical trials conducted in the United States and worldwide. Keywords were used alone and with the modifiers of treatment, novel therapies, castration-resistant prostate cancer, castrate-resistant prostate cancer, circulating tumor cells, and biomarkers. Bibliographies from these references

Table I Current treatment options for patients with castrationresistant prostate cancer ${ }^{2}$

Secondary hormonal therapies

Withdrawal responses (eg, antiandrogens, megestrol acetate)

Antiandrogen administration (flutamide, bicalutamide, nilutamide)

Adrenal suppressants (ketaconzole, aminoglutethimide)

Glucocorticoids (eg, dexamethasone, prednisone)

Estrogens (eg, DES, fosfestrol, estramustine)

Bisphosphonates (Zoledronate)

External-beam radiation therapy

Bone-seeking radiopharmaceuticals (samarium, strontium)

Chemotherapies (eg, mitoxantrone, docetaxel)

Experimental therapies

Abbreviation: DES, diethylstilbestrol. were reviewed. Criteria used for study selection included study design, English language, relevance to clinicians, and validity based on the venue of publication.

\section{Biomarkers of disease response to treatment}

In prostate cancer, reliable markers of disease status are important for selecting and monitoring treatment. Since most men with advanced CRPC have bone metastasis, these lesions are difficult to assess using the standard response evaluation criteria in solid tumors. Hence several other disease markers such as decrease in serum prostate-specific antigen (PSA; eg, major and minor responses of $\geq 50 \%$ and $\geq 25 \%$ to $49 \%$ PSA decrease from baseline, respectively), symptomatic improvement in bone pain (visual analog scale) or quality of life questionnaires have been used in clinical trials as indicators of clinical response and benefit. More recently, by using reverse transcriptase-polymerase chain reaction (RT-PCR) for PSA mRNA, detecting circulating PSA-producing prostate cancer cells have been shown in preliminary studies to have prognostic significance ${ }^{6}$ and this may become a useful tool in assessing response to treatment in the future.

\section{Serum prostate-specific antigen}

Most clinical trials ${ }^{7,8}$ in prostate cancer have used an improvement of $50 \%$ in the serum PSA as a marker of response. This is also commonly used to guide treatment decisions on individual patients. In about $5 \%-10 \%$ of patients, whose prostate cancers are associated with low serum PSA, a decline in PSA cannot be used as an indicator of response. Criteria for disease progression when using changes in PSA has been well defined by the Prostate Cancer Clinical Trials Working Group (PCWG2) ${ }^{7}$ and the Prostate-Specific Antigen Working Group (PSAWG) ${ }^{8}$ and this has also been validated by data-sets of two large Southwest Oncology Group Trials (SWOG 9346 and 9916). ${ }^{9}$ The following definitions are used to define progression:

1. In patients whose PSA has not decreased, progressive disease is a $25 \%$ increase over the baseline (on-study) and an increase in the absolute-value PSA level by at least $2 \mathrm{ng} / \mathrm{mL}$, which is confirmed by a second value.

2. In patients whose PSA has decreased but has not reached response criteria, progressive disease would be considered to have occurred when PSA increases $25 \%$ over the post-treatment nadir.

It is important to note that there can be an initial transient surge in serum PSA during the first six to eight 
weeks of treatment followed by disease stabilization and decrease in PSA.

\section{Serum clusterin levels in CRPC}

Clusterin, also known as apolipoprotein J, is a stress-induced cyto-protective chaperone protein expressed in virtually all human tissues..$^{10}$ Clusterin over-expression is demonstrated in various human malignancies including prostate, breast, lung, bladder, kidney, and colon cancers. ${ }^{11}$ In prostate cancer, clusterin levels are low in hormone-naïve tissue, but increase significantly after hormone therapy. ${ }^{12}$ Clusterin levels have also been correlated with preoperative PSA value and also the pathological grade on both biopsy and radical prostatectomy specimens. ${ }^{13}$ Further, clusterin expression has also been reported to be a possible predictor for biochemical recurrence following radical prostatectomy. ${ }^{14}$ In a recent phase II clinical trial, ${ }^{15}$ serum levels of clusterin was used a biomarker of response and was reported to be significantly reduced following treatment with OGX-011, an antisense oligonucleotide against clusterin. All these data put together suggest that clusterin could be used as a potential diagnostic and prognostic indicator and also a marker of response to treatment in CRPC with metastases, but needs to be evaluated in larger randomized studies.

\section{Fluoro-dihydrotestosterone positron emission tomography}

Fluoro-dihydrotestosterone (FDHT) is a biomarker of androgen receptor expression in human prostate cancer, and has been particularly useful in the setting of advanced prostate cancer, when the patient has castrate levels of circulating testosterone in the blood. Two small prospective studies have shown the feasibility of using FDHT scan with excellent imaging characteristics and a rapid uptake in the tumor at metastatic sites expressing androgen receptor with acceptable dosimetry. ${ }^{16-18}$ This scan is currently incorporated and compared to fluoro-deoxyglucose (FDG) positron emission tomography (PET) in a phase I/II study of novel small molecule androgen receptor antagonist MDV3100. ${ }^{19}$ Initial reports presented at the 2009 ASCO annual meeting showed a $>50 \%$ decline in the standardized uptake value $\left(\mathrm{SUV}_{\max }\right)$ on FDHT PET observed in 11 out of 12 of patients (92\%) at 4 and 12 weeks, while six patients $(50 \%)$ had a decreased $\mathrm{SUV}_{\text {max }}$ on FDG PET. ${ }^{20}$

\section{Role of circulating tumor cells}

Circulating tumor cells (CTCs) are epithelial cells that shed from different tumors. The CTC count is based on a test that works by using fluorescence labeled antibodies against epithelial cell adhesion molecules combined to microscopic iron particles, called ferrofluid. These antibody/ferrofluid combinations attach very specifically to CTCs. Powerful magnets then "pull" the CTCs out of the blood sample and they are then stained with additional bio-molecules and chemicals so that they can be positively identified as CTCs. This system, approved by the US Food and Drug Administration (FDA) is commercially available as CellSearch ${ }^{\mathrm{TM}}$ for monitoring of metastatic prostate cancer, metastatic breast and metastatic colorectal cancer patients. In a prospective study, De Bono and colleagues ${ }^{21}$ reported that CRPC patients with $\geq 5$ CTCs per $7.5 \mathrm{~mL}$ prior to chemotherapy had a significantly shorter median survival compared to those with $<5$ CTCs (10 vs 21 months). Also, changes in number of CTCs following chemotherapy correlated with prognosis. Patients who had $<5$ CTCs at baseline and at their last assessment had a median survival of more than 26 months, while those who had $\geq 5$ at baseline but then had $<5$ at their last assessment had a median survival of 21 months. In contrast, those with $\leq 5$ CTCs at an early assessment who had $\geq 5$ at their last assessment had a median survival of nine months, and those who had $\geq 5$ CTCs at all assessments had a median survival of only seven months. Two recent prospective studies have also validated that increased levels of circulating tumor cells predict worse outcomes in patients with metastatic CRPC. ${ }^{22}$ The CTC number, analyzed as a continuous variable, has a potential to be used to monitor disease status and might be useful as an intermediate endpoint of survival in clinical trials. Its role in treatment decisions need to be validated prospectively.

\section{Chemotherapy for CRPC First-line chemotherapy for CRPC}

Mitoxantrone, estramustine, and docetaxel are the three drugs which are currently approved by FDA for first-line chemotherapy in CRPC. Two pivotal trials which showed a survival benefit with Docetaxel have established the combination of Docetaxel and prednisone as the standard of care for men with CRPC.

In the landmark TAX-327 trial, 1006 chemotherapy-naïve CRPC patients were randomized to three different treatment arms - docetaxel $30 \mathrm{mg} / \mathrm{m}^{2}$ every week, docetaxel $75 \mathrm{mg} / \mathrm{m}^{2}$ every three weeks and mitoxantrone $12 \mathrm{mg} / \mathrm{m}^{2}$ every three weeks. All patients received prednisone $5 \mathrm{mg}$ orally twice a day. Patients receiving docetaxel every three weeks had a significant improvement of survival compared to weekly docetaxel and mitoxantrone (18.9 months vs 16.5 months; 
$P<0.009$ ). PSA response, pain control and quality of life were also significantly better with docetaxel every three weeks compared to mitoxantrone. ${ }^{23} \mathrm{An}$ update of the results of TAX-327 trial in 2007 showed a persistence of a survival benefit of docetaxel every three weeks compared to mitoxantrone and no survival benefit with the weekly docetaxel. At three years, survival was $17.2 \%$ for docetaxel every three weeks compared to $12.8 \%$ with mitoxantrone $(P=0.005) .{ }^{24}$

The Southwest Oncology Group (SWOG) 99-16 study also shows survival benefit with Docetaxel. 674 patients with metastatic CRPC were randomized to docetaxel/estramustine and Mitoxantrone/prednisone arms. Treatment regimen was $280 \mathrm{mg}$ of estramustine three times daily on days 1 through 5 , docetaxel $60 \mathrm{mg} / \mathrm{m}^{2}$ on day 2 in the docetaxel arm and $12 \mathrm{mg}$ of mitoxantrone $\mathrm{mg} / \mathrm{m}^{2}$ on day 1 plus $5 \mathrm{mg}$ of prednisone twice daily in the mitoxantrone arm. Docetaxel was reported to be superior to mitoxantrone with a median survival of 17.5 months vs 15.6 months $(P=0.02)$, median time to progression (6.3 vs 3.2 months; $P<0.001)$ and PSA declines of $50 \%$ (50\% vs $27 \% ; P<0.001)$. However, there was no significant objective tumor response difference between the two arms. ${ }^{25}$ These two trials showed a $20 \%-24 \%$ reduction in mortality in patients with CRPC docetaxel doublets (chemotherapy combinations).

Several chemotherapy agents in combination with docetaxel have been investigated in the first-line setting to improve PSA response and efficacy. Though there has been evidence of activity in phase II studies, none have demonstrated superiority to docetaxel/prednisone in phase III trials.

\section{Docetaxel-based combinations Docetaxel plus vinorelbine}

Vinorelbine, a semisynthetic vinca alkaloid, and docetaxel have demonstrated synergy in tumor cell lines and animal models. Efficacy and tolerability of the combination of vinorelbine and docetaxel for chemotherapy-naïve CRPC has been studied in several phase II trials. In a study of 21 patients treated with vinorelbine, $20 \mathrm{mg} / \mathrm{m}^{2}$ followed by docetaxel, $25 \mathrm{mg} / \mathrm{m}^{2}$, on days 1 and 8 of a 21 -day cycle, 18 patients who were evaluable for biochemical response with 11 patients having a $\geq 50 \%$ reduction in PSA. Of five patients with measurable disease, three were evaluable: one patient had a complete response, and two had partial responses at the site of measurable disease. ${ }^{26}$ Similar results were noted in another study with same chemotherapy regimen. In addition to PSA response, $42 \%$ of patients achieved a significant change in Karnofsky performance score (KPS) and positive pain response. ${ }^{27}$ More recently, two docetaxel doublets were compared in a randomized phase II trial. In this study, 64 chemotherapy-naive patients with CRPC were randomized to a three-week regimen of docetaxel $\left(20 \mathrm{mg} / \mathrm{m}^{2}\right.$, days 1 and 8$)$ and vinorelbine ( $25 \mathrm{mg} / \mathrm{m}^{2}$, days 1 and 8$)$ or docetaxel $\left(60-70 \mathrm{mg} / \mathrm{m}^{2}\right.$, day 1) and estramustine (280 mg oral thrice daily days 1-5) arms. The docetaxel/vinorelbine arm was inferior compared to the docetaxel/estramustine arm in terms of objective response rate (33\% vs $67 \%$ ), PSA response rate (33\% vs $43 \%$ ), and median survival (16.2 vs 19.7 months)..$^{28}$

\section{Docetaxel plus capecitabine}

Capecitabine has been combined with docetaxel because of its potential synergy with docetaxel. In a phase II study with 30 patients, docetaxel $36 \mathrm{mg} / \mathrm{m}^{2}$ administered on days 1 , 8 , and 15 , and capecitabine $1250 \mathrm{mg} / \mathrm{m}^{2}$ taken orally on days 5-18 every 28 days was shown to have a $>50 \%$ PSA decline sustained for at least four weeks in 19/27 (71\%) patients) with a $>90 \%$ PSA decline in $8 / 27$ (30\%) patients. Partial response per Response Evaluation Criteria in Solid Tumors (RECIST) was noted in 5/10 (50\%) evaluable measurabledisease patients. The regimen was tolerable with one grade 4 neutropenia and two patients with grade 3 hand-foot syndrome and no treatment-related deaths. ${ }^{29}$

\section{Docetaxel plus thalidomide}

Preclinical models have demonstrated significant activity of the combination of docetaxel and thalidomide in CRPC. In a phase II trial, 75 patients were randomly assigned to receive either docetaxel $30 \mathrm{mg} / \mathrm{m}^{2}$ weekly for three weeks, followed by a one-week rest period $(n=25)$; or docetaxel at the same dose and schedule, plus thalidomide $200 \mathrm{mg}$ orally each day $(n=50)$. This combination showed that the proportion of patients with a greater than $50 \%$ decline in PSA was higher in the docetaxel/thalidomide group (53\% in the combined group, $37 \%$ in docetaxel-alone arm). However, the progression-free survival (PFS) or overall survival (OS) was not different in the two groups. Toxicities except thromboembolic events were comparable to both groups. While there were no thromboembolic events in the docetaxel-alone group, 12 of the first 43 patients treated with the docetaxel/thalidomide combination developed either venous thrombosis $(n=9)$ or transient ischemic attack or stroke $(n=3)$. There was no thrombosis in the subsequent patients after the initiation of prophylactic anticoagulation with low-molecular-weight heparin. ${ }^{30}$ Currently, a phase II trial is underway evaluating the combination of docetaxel, 
bevacizumab, thalidomide and prednisone in CRPC. ${ }^{19}$ Preliminary results of this trial presented at the 2008 ASCO annual meeting are very encouraging. Sixty patients with progressive metastatic CRPC and no prior chemotherapy for CRPC were treated with docetaxel $75 \mathrm{mg} / \mathrm{m}^{2}+$ bevacizumab $15 \mathrm{mg} / \mathrm{kg}$ day 1 , every three weeks; thalidomide $200 \mathrm{mg}$ and prednisone $10 \mathrm{mg}$ was given orally daily. Median number of treatment cycles was $11(2-46)$. Fifty-one patients (88\%) had PSA declines of $\geq 50 \%$ and 41 patients $(71 \%)$ had a $\geq 80 \%$ PSA decline. The estimated median PFS was 18.2 months.

\section{Docetaxel plus carboplatin}

Platinum compounds have modest but distinct singleagent activity in patients with hormone-refractory prostate carcinoma. Its activity in combination with docetaxel was evaluated in a phase II study by $\mathrm{Oh}$ and colleagues in a Cancer and Leukemia Group B (CALGB) multicenter study, 40 patients were treated with oral estramustine $(240 \mathrm{mg}$ three times per day for five days), $70 \mathrm{mg} / \mathrm{m}^{2}$ of docetaxel, and carboplatin at a dose of area under the curve (AUC) 5. Granulocyte colony-stimulating factor (G-CSF) was used to minimize the neutropenia associated with this regimen. Each cycle was repeated every 21 days. Of the 34 evaluable patients, 23 (68\%) had a $\geq 50 \%$ decline in PSA and $20(59 \%)$ had a $\geq 75 \%$ decline. Twenty-one patients had measurable disease, with one complete $(5 \%)$ and 10 partial responses $(47 \%)$, for an overall measurable response rate of $52 \%$. The overall median time to disease progression was 8.1 months and the overall survival period was 19 months. ${ }^{31}$

\section{Docetaxel plus epirubicin}

Anthracyclines have shown some activity in CRPC as reported by the EORTC Genitourinary group. ${ }^{32}$ Epirubicin, at equipotent doses, is associated with quantitatively less severe toxicity than its parent compound. ${ }^{32}$ This agent has been studied by EORTC Genitourinary group in a phase II trial in combination with docetaxel. Docetaxel $30 \mathrm{mg} / \mathrm{m}^{2}$ and epirubicin $30 \mathrm{mg} / \mathrm{m}^{2}$ were administered on a weekly basis for a maximum of 24 cycles. The therapy was discontinued after the first 12 cycles in the patients who responded or had stable disease and was resumed as soon as any signs of progression were noted. Of the 38 evaluable patients, 26 (68.4\%) achieved a $\geq 50 \%$ decrease in PSA. The median response duration was 8.8 months, and the median time to progression was 7.4 months (95\% confidence interval [CI]: 5.6 to 9.6). Pain was rapidly reduced in 24 (72.7\%; 95\% CI: 54.2 to 86.7$)$ of the 33 patients who were symptomatic at baseline. The regimen was well tolerated. Grade 3 neutropenia occurred in $15.7 \%$ of the patients, grade 3 anemia in $13.1 \%$, and grade 3 thrombocytopenia in $7.8 \% .^{32,33}$

\section{Docetaxel plus calcitriol}

Prostate cancer cells express vitamin D receptor (VDR) for 1, 25 dihydroxy vitamin D. VDR activation is linked to more than 60 genes promoting pro-differentiation, antiproliferation, and apoptotic activity on prostate cancer cells. ${ }^{34,35}$ Calcitriol has been shown to potentiate the effect of cytotoxic therapy when combined with taxanes. The Androgenindependent prostate cancer Study of Calcitriol Enhancing Taxotere (ASCENT) trial was a double-blind, randomized, phase II study of DN-101 (Ascentar; a high-dose formulation of calcitriol) and weekly docetaxel compared with docetaxel alone. 250 patients with progressive CRPC were randomized to weekly docetaxel $36 \mathrm{mg} / \mathrm{m}^{2}$ for three weeks of a fourweek cycle combined with either $45 \mu \mathrm{g}$ DN-101 or placebo taken orally one day before docetaxel. The primary endpoint, $\geq 50 \%$ PSA decline within six months of enrollment, were seen in $58 \%$ in DN-101 patients and $49 \%$ in placebo patients $(P=0.16)$. Overall, the response rate was $63 \%$ for DN-101-treated patients and 52\% for placebo treated patients $(P=0.07)$. Patients in the DN-101 group had a hazard ratio for death of $0.67(P=0.04)$ in a multivariate analysis. On the basis of these results, a phase III trial (ASCENT-2) was initiated. This trial differed from the ASCENT-1 trial in that the control arm was changed to the standard every threeweek docetaxel regimen. A planned interim analysis found excess number of deaths among patients assigned to receive $\mathrm{DN}-101$, resulting in termination of the trial. ${ }^{19}$ At this point in time, DN-101's role in the treatment of prostate cancer remains uncertain.

\section{Docetaxel plus oblimersen}

The Bcl-2 family of proteins constitutes a critical intracellular checkpoint of apoptosis within a distal common cell death pathway. ${ }^{36}$ It is also thought to be involved in resistance to conventional cancer treatment. Oblimersen is an antisense oligodeoxynucleotide targeted against $\mathrm{Bcl} 2$. In a phase II study by Tolcher and colleagues, the combination of oblimersen sodium ( $7 \mathrm{mg} / \mathrm{kg} /$ day continuous infusion on days $1-8)$ and docetaxel $\left(75 \mathrm{mg} / \mathrm{m}^{2}\right.$ on day 6 , every three weeks) produced PSA response in 14 of $27(52 \%)$ patients with metastatic CRPC with a median survival of 19.8 months. Bcl-2 protein expression decreased, with a median of $49.9 \%$ in peripheral blood mononuclear cells post-treatment, but the individual incremental change did not correlate with either steady-state 
concentration of oblimersen or response. ${ }^{37}$ However, these promising findings were not supported by a recently reported randomized phase II study by the EORTC. ${ }^{38}$ In this trial, 115 patients with metastatic CRPC who had not received previous chemotherapy, were assigned to three-weekly therapy with either oblimersen sodium (7 mg/kg/day, days $1-7)$ plus docetaxel $\left(75 \mathrm{mg} / \mathrm{m}^{2}\right.$, day 5) or docetaxel (75 mg/m², day 5) alone, for up to 12 cycles. The proportion of patients with a PSA response was higher in the single-agent docetaxel arm than in the docetaxel plus oblimersen sodium arm (46\% vs $37 \%$ ). Interestingly, oblimersen added to docetaxel was associated with an increase in the incidence of grade $\geq 3$ fatigue, mucositis, and thrombocytopenia. Major toxic events were reported in $22.8 \%$ and $40.7 \%$ of patients with docetaxel and docetaxel-oblimersen, respectively. Another Bcl-2 inhibitor, AT-101, is currently being investigated in phase I/II studies with docetaxel. ${ }^{19}$

\section{Docetaxel plus custirsen (OGX-OII)}

Several studies have demonstrated clusterin overexpression in prostate cancer especially after hormone therapy. ${ }^{13,39}$ Clustein expression has also reported to be a possible predictor for biochemical recurrence following prostatectomy. ${ }^{14}$ An antisense oligonucleotide directed against clusterin (custirsen, OGX-011) has been developed, and successful downregulation of clusterin expression was shown in primary prostate cancers in a phase I study. ${ }^{40}$

Custirsen is further being evaluated in a randomized phase II study in combination with Docetaxel and prednisone in chemotherapy-naïve CRPC patients and preliminary data was reported at the 2009 ASCO annual meeting. ${ }^{15}$ Docetaxel $75 \mathrm{mg} / \mathrm{m}^{2}$ every three weeks along with custirsen $640 \mathrm{mg}$ IV weekly (arm A) was compared to docetaxel (arm B). PSA response rate was the primary endpoint; progression-free survival and overall survival were secondary endpoints. Data of 82 patients enrolled between September 2005 and December 2006 was reported. PSA response rate was $58 \%$ in arm A and 54\% in arm B. Significant decrease in mean serum clusterin levels measured on day 1 of cycle 2 was noted with custirsen $(-18 \%$ in arm A and $+8 \%$ in arm $\mathrm{B} ; P=0.0005)$. After a median follow-up of 32 months, overall survival (27.5 months vs 16.9 months, hazard ratio $=0.60 ; P=0.07$ ) showed trend towards superiority with custirsen, while progression-free survival was similar between the two arms (7.3 vs 6.1 months). Major adverse events noted with custirsen include fatigue, fever, rigors, diarrhea, and rash.

\section{Other cytotoxic agents}

\section{Epothilones}

The epothilones are a new class of nontaxane tubulin polymerizing agents. ${ }^{41}$ Two epothilones, ixabepilone and patupilone, in clinical studies, have shown significant activity in men with CRPC. ${ }^{42-45}$ A phase II study conducted by the Southwest Oncology Group (SWOG) included 42 men with chemotherapy-naive CRPC who received ixabepilone $\left(40 \mathrm{mg} / \mathrm{m}^{2}\right)$ every three weeks. ${ }^{43}$ PSA decline $\geq 50 \%$ was noted in 14 patients $(33 \%) .72 \%$ of PSA responders had declines greater than $80 \%$, and two patients achieved an undetectable PSA. The estimated median PFS was six months and the median survival was 18 months. Major toxicities were neutropenia and neuropathy. Phase III trials with Ixabepilone are in development.

A randomized multicenter phase II trial of patupilone (at two different doses, $8 \mathrm{mg} / \mathrm{m}^{2}$ or $10 \mathrm{mg} / \mathrm{m}^{2}$ given every three weeks) vs docetaxel in CRPC is currently underway. ${ }^{19}$

\section{Eribulin}

Eribulin mesylate (E7389), a synthetic analog of halichondrin $\mathrm{B}$, is a nontaxane inhibitor of microtubule dynamics exerting its anticancer effects by triggering apoptosis of cancer cells following prolonged mitotic blockage. ${ }^{46}$ In a multicenter, open-label, single-arm, phase II study, patients with metastatic CRPC, stratified by prior taxane exposure, received eribulin mesylate $1.4 \mathrm{mg} / \mathrm{m}^{2}$ on days 1 and 8 of a 21-day cycle. No steroid premedication or concomitant medication was administered. Of 108 patients evaluable for safety, 58 were taxane-naïve. Primary endpoint of PSA response rate defined as two consecutive $\geq 50 \%$ decreases in PSA levels from baseline was noted in 14 taxane-naïve patients (22.8\%) and four taxane pretreated patients $(8.7 \%)$. Commonly noted side effects were myelosupression (with $22.4 \%$ grade $3 / 4$ neutropenia), fatigue and peripheral neuropathy. ${ }^{47}$

\section{Src inhibitors \\ Dasatinib}

The Src-family kinases are the largest family of nonreceptor protein tyrosine kinases and are responsible for signal transduction during many cellular activities, including differentiation, adhesion, and migration. Aberrant Src kinase activity has been widely implicated in development of prostate and several other cancers. ${ }^{48}$ Src signaling is involved in androgen-induced proliferation of prostate cancer in cancer tissue from patients with castration-refractory prostate cancer. ${ }^{49,50}$ Aberrant SFK signaling is therefore implicated across multiple stages and models of prostate cancer. Antiproliferative 
and antiosteoclastic activity from preclinical models show potential for dasatinib, an oral SRC and SRC family kinase inhibitor, as a targeted therapy for patients with prostate cancer. $^{51}$

Dasatinib was evaluated in a phase II study in chemotherapy-naïve patients with metastatic CRPC. ${ }^{52}$ Forty-seven patients were enrolled. Dasatinib was initially administered at a dose of $100 \mathrm{mg}$ orally twice daily. After the first 25 patients were enrolled, the dosage was reduced to $70 \mathrm{mg}$ twice daily for subsequent patients $(\mathrm{n}=22)$. This change occurred due to observations in other clinical trials with dasatinib where lower doses of dasatinib resulted in equal efficacy but improved tolerability. Patients were treated with dasatinib until progression of disease, unacceptable toxicity at the lowest allowable dose reduction (100 mg once daily) despite optimal supportive care. Progression was defined as tumor progression by RECIST or by at least one definite new lesion on bone scan. The study protocol allowed patients with asymptomatic increases in PSA without other evidence of progression (RECIST or clinical symptoms), to continue therapy. Endpoints included changes in PSA levels, bone scans, measurable disease, and markers of bone metabolism. Lack of progression according to RECIST and bone scan was determined as per Prostate Cancer Working Group 2 guidelines, and reported at 12 and 24 weeks. Lack of progression was noted in $20(43 \%)$ patients at week 12 and in nine (19\%) patients at week 24 . Nearly half of the patients showed a decrease in both the markers of bone metabolism (N-telopeptide and bone alkaline phosphatase) by week 12 . This study provides encouraging evidence of the activity of dasatinib in chemotherapy-naive patients with metastatic CRPC. As a result of this trial, an ongoing phase III randomized clinical trial is evaluating the effects of the addition of dasatinib to docetaxel on overall survival and skeletal-related events. ${ }^{19}$

\section{Vaccine-based immune therapies GVAX (CG I940/CG87II)}

GVAX immunotherapy for prostate cancer is comprised of two prostate tumor cell lines that have been modified to secrete granulocyte-macrophage colony-stimulating factor (GM$\mathrm{CSF}$ ), an immune stimulatory cytokine that plays a key role in stimulating the body's immune response, and then irradiated for safety. Two phase III trials (VITAL-1 and VITAL-2) have evaluated GVAX against docetaxel/prednisone in chemotherapy naïve CRPC. Both the study results were presented at the 2009 ASCO Genitourinary symposium. ${ }^{53,54}$ Six hundred twenty-six chemotherapy-naïve CRPC patients without cancer-related pain were randomized to receive GVAX (CG1940/CG8711, 500 million cells prime/300 million cells boost doses every two weeks for 13 cycles followed by maintenance every four wks) or docetaxel $\left(75 \mathrm{mg} / \mathrm{m}^{2}\right.$ every three weeks)/prednisone (10 mg daily). The study was prematurely terminated in October 2008 based on the results of a futility analysis conducted by the study's Independent Data Monitoring Committee (IDMC), which determined that the study had less than a $30 \%$ chance of meeting its predefined primary endpoint of improvement in overall survival. The study completed accrual of 626 patients in 2007, and all completed the initial six-month treatment period. At the time of study termination the median follow-up was 66 weeks. Grade 3 or higher related adverse events were $8.8 \%$ on the vaccine arm vs $43 \%$ on the docetaxel arm. No difference in median survival was observed (20.7 vs 21.7 months; $P=0.78$ ). In the subset of men with Halabi predicted survival (HPS) $>18$ months, median survival was prolonged on GVAX compared to docetaxel (29.7 vs 27.1 months; $P=0.60$ ). While overall survival was not significantly improved compared to chemotherapy, a late favorable effect of GVAX is suggested by crossover of the Kaplan-Meier survival curve for GVAX above docetaxel at approximately 22 months.

In the second phase II trial, VITAL-2, taxane-naïve CRPC patients with pain requiring opioid analgesics were eligible. Docetaxel ( $75 \mathrm{mg} / \mathrm{m}^{2}$ every three weeks) was given in both arms. Prednisone (10 mg daily) was given in the control arm. GVAX (CG1940/CG8711, 500 million cells prime/300 million cells boost doses every three weeks for 10 cycles) was administered two days following each docetaxel infusion in the experimental arm followed by maintenance immunotherapy alone every four weeks. The study was prematurely terminated in August 2008 after accrual of 408 patients due to an imbalance in deaths between the two treatment arms of the study, with 67 deaths in the docetaxel/vaccine arm and 47 deaths in the docetaxel/ prednisone arm. Median predicted survival based on the HPS was 13 months in both arms. No significant toxicities in the docetaxel/vaccine arm were observed that could explain the imbalance in deaths. $85 \%$ of deaths were reported as due to prostate cancer in both arms. The imbalance was restricted to deaths from prostate cancer and to patients with evidence of PSA progression at time of death. Overall survival was shorter in the docetaxel/vaccine arm with median survival of 12.2 months vs 14.1 months in the docetaxel/prednisone $\operatorname{arm}(P=0.0076)$. Exploratory analyses to identify subgroups of patients with preferential benefit from the investigational therapy are underway. 


\section{Active phase III trials in first-line chemotherapy for CRPC}

Several novel agents and combinations with docetaxel are currently being studied in phase III clinical trials for first-line chemotherapy for CPRC as listed in Table 2.

\section{Second line chemotherapy for CRPC}

Patients whose tumors progress through first-line chemotherapy have very limited treatment options. Mitoxantrone, an anthraquinone structurally related to the anthracyclines, may retain some utility in patients who have progressed on docetaxel. Indeed, mitoxantrone was the first cytotoxic agent to be approved for palliative treatment of men with CRPC. ${ }^{55-57}$ Other agents have been tested in a phase II setting and they have been reviewed elsewhere. ${ }^{58}$ There are now several new agents being reported and currently tested in this setting.

\section{Docetaxel-based chemotherapy}

\section{combinations}

\section{Docetaxel plus bevacizumab}

Angiogenesis has a vital role in progression of CRPC. The plasma level of vascular endothelial growth factor (VEGF) is shown to be an independent predictor of survival of CRPC. ${ }^{59}$ In a phase II study reported by Di Lorenzo and colleagues ${ }^{60}$ of the 20 highly pretreated patients with CPRC who received, bevacizumab $(10 \mathrm{mg} / \mathrm{kg})$ and docetaxel $\left(60 \mathrm{mg} / \mathrm{m}^{2}\right)$ every three weeks, 11 patients $(55 \%)$ had major
PSA responses, and three (37.5\%) had objective responses. Importantly, seven major PSA responses $(>50 \%$ PSA decline) were recorded in the same patients who had reported a $>50 \%$ PSA decrease after first-line docetaxel and four major PSA responses were observed in patients previously nonresponsive to docetaxel alone. This study demonstrates that reintroduction of docetaxel after a drug-free interval is feasible and effective in docetaxel pretreated patients. The role of bevacizumab in docetaxel-pretreated patients needs to be further evaluated in a larger, phase III trial.

Sorafenib, a multitarget tyrosine kinase inhibitor (TKI) with antiangiogenic activity via VEGF receptor (VEGFR), platelet-derived growth factor receptor (PDGFR), c-Kit, and Flt3 as a single agent has been tested on 22 patients with CRPC. No biologic response has been observed while on treatment, but surprisingly, a PSA decrease has been observed in five patients when treatment was stopped. In addition, two patients have had a major bone response despite absence of biologic response. ${ }^{61}$

\section{Single cytotoxic agents \\ Satraplatin}

Satraplatin is an orally active third-generation platinum compound that has significant activity in cisplatin-resistant tumor models. Activity in prostate cancer was suggested in early clinical studies. ${ }^{62}$ Two randomized phase III trials have evaluated satraplatin in CRPC. In the first study by Sternberg and colleagues, ${ }^{63}$ satraplatin at a dose of $100 \mathrm{mg} / \mathrm{m}^{2}$ for five days every four weeks and prednisone was compared

Table 2 Active phase III trials in first-line chemotherapy for CRPC ${ }^{19}$

\begin{tabular}{|c|c|c|c|c|}
\hline Study identifier & Study drug & Mechanism of action & Start date & Primary endpoint \\
\hline NCT00255606 & $\begin{array}{l}\text { Docetaxel/Prednisone } \\
\text { every } 3 \text { weekly vs } 2 \text { weekly } \\
\text { (PROSTY) }\end{array}$ & $\begin{array}{l}\text { Taxane (antimitotic, } \\
\text { antimicrotubule agent) }\end{array}$ & Aug-05 & TTF \\
\hline NCT00887I98 & $\begin{array}{l}\text { Abiraterone Acetate } \\
+ \text { Prednisone }\end{array}$ & CYPI7AI inhibitor & Apr-09 & OS, PFS \\
\hline $\begin{array}{l}\text { NCT00554229 } \\
\text { NCT00617669 }\end{array}$ & $\begin{array}{l}\text { ZD4054 (ENTHUSE } \\
\text { M0; ENTHUSE MI) }\end{array}$ & $\begin{array}{l}\text { Endothelin A receptor } \\
\text { antagonist }\end{array}$ & Nov-07 & OS \\
\hline NCT00744497 & $\begin{array}{l}\text { Docetaxel/Prednisone } \\
\text { + Dasatinib }\end{array}$ & $\begin{array}{l}\text { Multi-target Tyrosine Kinase } \\
\text { inhibitor }\end{array}$ & Oct-08 & OS \\
\hline NCT00II 0214 & $\begin{array}{l}\text { Docetaxel/Prednisone } \\
+ \text { Bevacizumab }\end{array}$ & $\begin{array}{l}\text { VEGF blocking monoclonal } \\
\text { antibody }\end{array}$ & Apr-05 & OS \\
\hline NCT00I34056 & $\begin{array}{l}\text { Docetaxel/Prednisone } \\
+ \text { Atrasentan }\end{array}$ & $\begin{array}{l}\text { Endothelin A receptor } \\
\text { antagonist }\end{array}$ & Aug-06 & PFS \\
\hline NCT00626548 & $\begin{array}{l}\text { Docetaxel/Prednisone } \\
\text { + ZD4054 }\end{array}$ & $\begin{array}{l}\text { Endothelin A receptor } \\
\text { antagonist }\end{array}$ & Jan-08 & OS \\
\hline NCT005I9285 & $\begin{array}{l}\text { Docetaxel/Prednisone } \\
+ \text { Aflibercept (VENICE) }\end{array}$ & $\begin{array}{l}\text { Soluble decoy receptor } \\
\text { forVEGF }\end{array}$ & Aug-07 & OS \\
\hline
\end{tabular}

Abbreviations: CRPC, castration-resistant prostate cancer; OS, overall survival; PFS, progression-free survival. 
with prednisone alone. The study was closed prematurely because of the sponsor's decision not to pursue the drug's development. The ad hoc analysis of the 50 enrolled participants showed a significant improvement in PFS favoring the satraplatin arm (5.2 vs 2.5 months). Median OS also favored the satraplatin arm (14.9 vs 11.9 months). These results led to a second phase III study, the SPARC trial. ${ }^{64}$ This study used a lower dose of satraplatin $\left(80 \mathrm{mg} / \mathrm{m}^{2}\right.$ for five days every four weeks) in combination with prednisone vs placebo and prednisone. 950 patients with CRPC progressing through prior cytotoxic chemotherapy were randomized in a 2:1 ratio. Significantly higher PSA decline (25.4 vs $12.2 \%$; $P<0.001$ ), pain response (24.2 vs $13.8 \%$; $P<0.005$ ), time to pain progression (66.1 vs 22.3 weeks; $P<0.001$ ) and PFS (11 vs 9.7 weeks) with a $33 \%$ reduction in the overall risk of disease progression all favored the satraplatin arm. However, OS was not statistically significant between the two arms (61.3 vs 61.4 weeks; $P=0.80$ ), resulting in a halt in further development. Treatment was generally well tolerated, with myelo-suppression being the major cause of grade 3 or 4 adverse events in satraplatin-treated patients.

\section{Epothilones}

Patupilone, a semi-synthetic derivative of epothilone B, has been studied in a multicenter, two-stage design phase II trial in patients with CRPC progressing within six months of docetaxel treatment. Patupilone was given at a dose of $10 \mathrm{mg} / \mathrm{m}^{2}$ IV every three weeks. As reported by Beardsley and colleagues, PSA declines of more than $50 \%$ were seen in 35 of 78 (45\%) patients. Grade 3 and 4-related adverse events at this dose included fatigue (16\%), diarrhea (13\%) and anorexia (5\%) and there were no grade 3 or 4 hematologic adverse events. ${ }^{65}$ In a multicenter phase II study, Ixabepilone $\left(35 \mathrm{mg} / \mathrm{m}^{2}\right)$ given every three weeks was compared with mitoxantrone $\left(14 \mathrm{mg} / \mathrm{m}^{2}\right)$ given every three weeks. PSA declines of more than $50 \%$ were seen in $17 \%$ of ixabepilone-treated patients and $20 \%$ of mitoxantrone-treated patients. Prior taxane response was associated with increased likelihood of second-line therapy response with ixabepilone. OS was similar in both groups, 10.4 months for ixabepilone and 9.8 months for mitoxantrone. ${ }^{66}$

\section{Novel targets}

\section{Endothelin-receptor antagonists}

Endothelins (endothelin-1, endothelin-2, and endothelin3) are regulators of cell proliferation, vasomotor tone, and angiogenesis. The endothelins bind to two receptors, endothelin-A and endothelin-B, and play a major role in tumor growth, proliferation, apoptosis, angiogenesis, and bone metastasis. ${ }^{67}$ Patients with metastatic prostate cancer have elevated levels of plasma endothelin-1 compared with patients with organ-confined cancer. Endothelin-A is thought to promote osteoblastic activity characteristic of bone metastases in prostate cancer. ${ }^{68}$

Atrasentan, predominantly an endothelin-A receptor antagonist was studied in two phase III trials. In the first study, 809 patients with CRPC were randomized to atrasentan $10 \mathrm{mg}$ daily vs placebo.$^{69}$ The primary endpoints were timeto-progression (TTP) which was determined according to radiographic and clinical measures. Atrasentan did not reduce the risk of disease progression relative to the placebo (hazard ratio, $0.89 ; P=0.136$ ). In exploratory analyses, however, bone alkaline phosphatase and PSA levels were significantly lower in the atrasentan arm. Atrasentan generally was tolerated well, and the most common adverse events associated with treatment were headache, rhinitis, and peripheral edema, reflecting the vasodilatory and fluid-retention properties of endothelin-A receptor blockade. In a second phase III trial, 941 men with PSA-only CRPC were randomized to receive atrasentan $10 \mathrm{mg}$ daily vs placebo.

Though not statistically significant, fewer patients treated with atrasentan experienced disease progression compared with placebo $(P=0.288)$ and the median survival was longer for the atrasentan group $(P=0.176)$. Although it did not meet the primary endpoint expectations, atrasentan did have an impact on molecular markers that indicate disease progression. There was improvement in bone alkaline phosphatase $(-1.51$ IU/L (A) vs $+2.2 \mathrm{IU} / 1(\mathrm{P}) ; P=0.001)$ and PSA doubling time was delayed $(P=0.031)$. An ongoing phase III study, the Southwest Oncology Group trial (SWOG S0421) is evaluating atrasentan in combination with docetaxel/prednisone as a first-line treatment in metastatic CRPC (Table 2). ${ }^{19}$

Zibotentan (ZD4054) is a selective endothelin-A receptor antagonist which was reported in a phase III trials to have similar results to atrasentan. No improvement in TTP was seen in 308 symptomatic patients with CRPC who were randomized to two doses of ZD4054, 15 or $10 \mathrm{mg}$, once daily or placebo. However, an interim analysis revealed an improvement in OS (23.5, 24.5 vs 17.3 months for placebo). Side effect profile was similar to atrasentan. On the basis of these encouraging results, three phase III trials (ENTHUSE) involving 2500 patients are currently being conducted in CRPC with ZD4054.

\section{Abiraterone}

Several preclinical and clinical studies have shown that despite being "hormone refractory", prostate cancer cells 
continue to express high androgen receptor expression and thus mediate androgen signaling. ${ }^{5}$ Abiraterone acetate is a potent and a highly selective irreversible inhibitor of cytochrome P-17 (17 a hydroxylase and C17,20-lyase), a dual enzyme that blocks adrenal androgen production. ${ }^{70}$

In a study of 58 patients who had progressive, metastatic CRPC and had failed hormonal therapy and up to two cytotoxic regimens, including docetaxel, were treated with abiraterone (1,000 mg once daily) and prednisone (5 mg twice daily). Twenty-five of 56 patients (45\%) had a PSA decline $\geq 50 \%$. Median time to PSA progression was 169 days. The majority of abiraterone-related adverse events were grades 1-2 and no grade 4 adverse events were reported. Also noted was a significantly better PSA response in ketoconazole-naïve postdocetaxel CRPC population. A randomized phase III pivotal study to confirm these results is ongoing. ${ }^{19}$

\section{MDV3100}

MDV3100 is a novel AR antagonist selected for activity in prostate cancer model systems with overexpressed AR. In contrast to bicalutamide, MDV3100 blocks nuclear translocation of AR and DNA binding, and has no known agonist activity when AR is overexpressed. ${ }^{71}$ Antitumor activity of MDV3100 in a phase I/II trial was reported at the 2009 ASCO annual meeting. ${ }^{20}$ One hundred forty patients with progressive CRPC were enrolled in sequential cohorts of 3-6 patients at 30, 60, 150, 240, 360, 480, and $600 \mathrm{mg} /$ day. Once the safety of a dose was established, enrollment was expanded at doses $\geq 60 \mathrm{mg} /$ day to include 12 chemotherapynaïve and 12 post-chemotherapy patients per cohort. Efficacy was assessed by PSA, circulating tumor cells (CTC), and time on treatment. PSA declines ( $\geq 50 \%$ from baseline) were observed at week 12 in 57\% (37/65) of naïve and $45 \%$ (22/49) of post-chemo patients. CTC counts on 101 of 114 patients showed $92 \%(56 / 61)$ with favorable $(<5)$ counts pretreatment maintained favorable post-treatment counts, while 53\% (21/40) converted from unfavorable to favorable post-treatment. For post-chemo patients, favorable retention was $100 \%$ (17/17) and unfavorable to favorable conversion at 240 and $360 \mathrm{mg} /$ day was $60 \%$ (6/10). Based on these results, MDV3100 appears to be promising candidate for treatment of advanced prostate cancer.

\section{Vaccines based immune therapy Sipuleucel-T}

Sipuleucel-T (Provenge, APC8015) contains mature, autologous antigen-presenting cells (APCs). APCs are obtained from the patient via a standard leukapheresis procedure approximately two days before each scheduled infusion. The patient's APCs are co-cultured with a recombinant fusion protein containing prostatic acid phosphatase (PAP). The activated, antigen-loaded APCs are then infused into the patient, where it can potentially stimulate a $\mathrm{T}$ cell response against prostate cancer cells. The process is performed three times over the course of a four-week period. The vaccine has been studied in three phase III clinical trials. In the first phase III study, D9901, consisting of 127 men with asymptomatic, metastatic CRPC, compared sipuleucel-T every two weeks for three cycles with placebo in a $2: 1$ ratio. The final three-year follow-up of the D9901 phase III study showed a median survival benefit of 4.5 months and a threefold improvement in survival at 36 months for patients who were randomized to receive Provenge. ${ }^{72}$ In another similar phase III trial, D9902, 98 men with asymptomatic, metastatic CRPC demonstrated a $20 \%$ improvement in OS for patients randomized to sipuleucel-T. In both studies, the vaccine was well tolerated, and the most common adverse events were fever and chills. The third phase III trial, D9902B, also known as the IMPACT trial (Immunotherapy for Prostate Adenocarcinoma Treatment) was a randomized, double-blind, placebo-controlled study comparing Provenge with placebo in 512 men with CRPC randomized in 2:1 ratio. The results were presented at the 2009 American Urological Association Annual Meeting. The median overall survival favored the vaccine arm with a 4.1-month increase in overall survival for patients treated with sipuleucel-T (25.8 vs 21.7 months; $P=0.032$ ). Also, 31.7 percent of sipuleucel-T patients were alive at three years as compared to $23.0 \%$ of placebo patients. An integrated analysis of all the three phase III trials, sipuleucel-T reduced the risk of death from any cause by $26.5 \%$ $(P<0.001)$ and extended median overall survival by 3.9 months compared with placebo. The 36-month overall survival was $33 \%$ in the sipuleucel-T group and $20 \%$ in the placebo group. Sipuleucel-T is the first active immunotherapy to demonstrate an improvement in overall survival for advanced prostate cancer. Given the short duration of the therapy (one month) and its favorable benefit-to-risk ratio, sipuleucel-T provides an attractive new option for the management of advanced prostate cancer. The drug is presently undergoing evaluation by the FDA for approval.

\section{Active phase III trials in second-line chemotherapy for CRPC}

Several novel agents and combinations with docetaxel are currently being studied in phase III clinical trials for secondline chemotherapy for CPRC as listed in Table 3. 
Table 3 Active phase III trials in second-line chemotherapy for CRPC ${ }^{19}$

\begin{tabular}{|c|c|c|c|c|}
\hline Study identifier & Study drug & Mechanism of action & Start date & Primary endpoint \\
\hline NCT00638690 & Abiraterone Acetate + Prednisone & CYPI7AI inhibitor & Apr 2009 & OS \\
\hline NCT009743II & MDV3I00 (AFFIRM) & AR antagonist & Sep 2009 & OS \\
\hline NCT00861614 & Ipilimumab & $\begin{array}{l}\text { CTLA-4 blocking } \\
\text { monoclonal antibody }\end{array}$ & May 2009 & OS \\
\hline NCT0065442 & Sipuleucel-T & $\begin{array}{l}\text { Active cellular } \\
\text { immunotherapy }\end{array}$ & Jul 2003 & Safety and efficacy \\
\hline NCT00676650 & Sunitinib + Prednisone & $\begin{array}{l}\text { Multitarget Tyrosine } \\
\text { Kinase inhibitor }\end{array}$ & Jul 2008 & OS \\
\hline NCT004I7079 & $\begin{array}{l}\text { XRP6258 + Prednisone } \\
\text { vs Mitoxantrone + Prednisone }\end{array}$ & $\begin{array}{l}\text { Taxane with a low } \\
\text { affinity for P-gP }\end{array}$ & Dec 2006 & OS \\
\hline
\end{tabular}

Abbreviations: CRPC, castration-resistant prostate cancer. OS, overall survival.

\section{Conclusions}

With the benefits of docetaxel-based therapy, more men are likely to be offered chemotherapy for CRPC. Treatment decisions for patients with advanced prostate cancer, which were largely palliative, have now changed in the light of TAX 327 and SWOG 9916 studies. The recent updates on the results of these studies suggest significant survival advantage and also improved quality of life. The exact timing when chemotherapy in the metastatic setting should be given is still an open question. Several newer docetaxel-based combinations, novel targeted treatments and vaccines are quite promising; nonetheless, these treatment options have not shown a significant survival improvement. Their role in the treatment of CRPC still needs to be validated by phase III trials, which are currently ongoing. Also, the exact utility and relevance of novel biomarkers calls for a larger prospective validation. The future is very promising for the clinical trials of today to become the standard-of-care treatments of tomorrow. Over the past decade, our understanding of molecular basis of androgen resistance and patho-biology of CRPC has been advancing, leading to novel agents that specifically target these pathways. In view of the multitude of questions still unanswered, every patient with CRPC should be encouraged to participate in clinical trials. Patients, physicians and families should support each other in the quest to eradicate and cure more patients and minimize mortality of CRPC.

\section{Disclosures}

Winston Tan received research support from Sanofi-Aventis, Pfizer, Genentech.

\section{References}

1. American Chemical Society. Website. Available from: http://www.acs. org/. Accessed on December 10, 2009.

2. DeVita VT, Lawrence TS, Rosenberg SA. Cancer Principles and Practice of Oncology. 8th ed. 2008;1392-1445.
3. Cancer of the prostate. Tables and figures \#23. 2009. Available from: http://seer.cancer.gov/csr/1975_2006/results_merged/sect_23_prostate. pdf. Accessed on December 10, 2009.

4. Lassi K, Dawson NA. Emerging therapies in castrate-resistant prostate cancer. Curr Opin Oncol. 2009;21:260-265.

5. Attar RM, Takimoto CH, Gottardis MM. castration-resistant prostate cancer: locking up the molecular escape routes. Clin Cancer Res. 2009; 15(10):3251-3255.

6. Helo P, Cronin AM, Danila DC, et al. Circulating prostate tumor cells detected by RT-PCR in men with localized or castration-refractory prostate cancer: concordance with CellSearch assay and association with bone metastases and with survival. Clin Chem. 2009;55(4):765-773.

7. Scher HI, Morris MJ, Kelly WK, et al. Design and end points of clinical trials for patients with progressive prostate cancer and castrate levels of testosterone: recommendations of the Prostate Cancer Clinical Trials Working Group. J Clin Oncol. 2008;26(7):1148-1159.

8. Bubley GJ, Carducci M, Dahut W, et al. Eligibility and response guidelines for phase II clinical trials in androgen-independent prostate cancer: recommendations from the Prostate-Specific Antigen Working Group. J Clin Oncol. 1999;17(11):3461-3467.

9. Hussain M, Goldman B, Tangen C, et al. Prostate-specific antigen progression predicts overall survival in patients with metastatic prostate cancer: data from Southwest Oncology Group Trials 9346 (Intergroup Study 0162) and 9916. J Clin Oncol. 2009;27(15):2450-2456.

10. Trougakos IP, Gonos ES. Clusterin/apolipoprotein J in human aging and cancer. Int J Biochem Cell Biol. 2002;34(11):1430-1448.

11. So A, Hadaschik B, Sowery R, et al. The role of stress proteins in prostate cancer. Curr Genom. 2007;8(4):252-261.

12. Miyake H, Yamanaka K, Muramaki M, et al. Enhanced expression of the secreted form of clusterin following neoadjuvant hormonal therapy as a prognostic predictor in patients undergoing radical prostatectomy for prostate cancer. Oncol Rep. 2005;14(5):1371-1375.

13. Zellweger T, Miyake H, July LV, et al. Chemosensitization of human renal cell cancer using antisense oligonucleotides targeting the antiapoptotic gene clusterin. Neoplasia. 2001;3(4):360-367.

14. Pins MR, Fiadjoe JE, Korley F, et al. Clusterin as a possible predictor for biochemical recurrence of prostate cancer following radical prostatectomy with intermediate Gleason scores: a preliminary report. Prostate Cancer Prostatic Dis. 2004;7(3):243-248.

15. Chi KN, Hotte SJ, Yu E, et al. Mature results of a randomized phase II study of OGX-011 in combination with docetaxel/prednisone vs docetaxel/prednisone in patients with metastatic castration-resistant prostate cancer. J Clin Oncol. 2009;27(15s): Abstract \# 5012.

16. Dehdashti F, Picus J, Michalski JM, et al. Positron tomographic assessment of androgen receptors in prostatic carcinoma. Eur J Nucl Med Mol Imaging. 2005;32(3):344-350.

17. Larson SM, Morris M, Gunther I, et al. Tumor localization of 16b-18FFluoro-5b-dihydrotestosterone vs $18 \mathrm{~F}-\mathrm{FDG}$ in patients with progressive, metastatic prostate cancer. J Nucl Med. 2004;45(3):366-373. 
18. Morris MJ, Schoder H, Smith-Jones P, et al. Pilot trial of [18F]fluorodihydro-testosterone (FDHT) and [18F]fluoro-2-deoxy-D-glucose (FDG) PET imaging in patients with castrate metastatic prostate cancer (CMPC). Proc Am Soc Clin Oncol. (2006 Prostate Cancer Symposium); Abstract \#144.

19. National Institutes of Health. Clinical Trials. 2009. Available from: http://clinicaltrials.gov/. Accessed on December 10, 2009.

20. Scher HI, Beer TM, Higano CS, et al. Antitumor activity of MDV3100 in a phase I/II study of castration-resistant prostate cancer (CRPC). J Clin Oncol. 2009;27(15s): Abstract \#5011.

21. de Bono JS, Scher HI, Montgomery BR, et al. Circulating tumor cells predict survival benefit from treatment in metastatic castration-resistant prostate cancer. Clin Cancer Res. 2008;14(19):6302-6309.

22. Groves-Kirkby N. Biomarkers: Circulating tumor cells in prostate cancer. Nature Rev Urol. 2009;6(5):238.

23. Tannock IF, de Wit R, Berry W, et al. Docetaxel plus prednisone or mitoxantrone plus prednisone for advanced prostate cancer. $N$ Engl J Med. 2004;351(15):1502-1512.

24. Berthold DR, Pond G, de Wit R, et al. Docetaxel plus prednisone or mitoxantrone plus prednisone for advanced prostate cancer: Updated survival of Tax 327. J Clin Oncol. 2007;25(18s): Abstract \#5005.

25. Petrylak DP, Tangen CM, Hussain MH, et al. Docetaxel and estramustine compared with mitoxantrone and prednisone for advanced refractory prostate cancer. $N$ Engl J Med. 2004;351(15):1513-1520.

26. Koletsky AJ, Guerra ML, Kronish L. Phase II study of vinorelbine and low-dose docetaxel in chemotherapy-naive patients with hormonerefractory prostate cancer. Cancer J. 2003;9(4):286-292.

27. Di Lorenzo G, Pizza C, Autorino R, et al. Weekly docetaxel and vinorelbine (VIN-DOX) as first line treatment in patients with hormone refractory prostate cancer. Eur Urol. 2004;46(6):712-716.

28. Hahn NM, Marsh S, Fisher W, et al. Hoosier Oncology Group randomized phase II study of docetaxel, vinorelbine, and estramustine in combination in hormone-refractory prostate cancer with pharmacogenetic survival analysis. Clin Cancer Res. 2006;12(20):6094-6099.

29. Vaishampayan UN, Heilbrun H, Eliason J, et al. Phase II trial of docetaxel and capecitabine combination in metastatic androgen independent prostate cancer (AIPC). Proc Am Soc Clin Oncol. (2007 Prostate Cancer Symposium); Abstract \# 239.

30. Dahut WL, Gulley JL, Arlen PM et al. Randomized phase II trial of docetaxel plus thalidomide in androgen-independent prostate cancer. J Clin Oncol. 2004;22(13):2532-2539.

31. Oh WK, Halabi S, Kelly KW et al. A phase II study of estramustine, docetaxel, and carboplatin with granulocyte-colony-stimulating factor support in patients with hormone-refractory prostate carcinoma: Cancer and Leukemia Group B 99813. Cancer. 2003;98(12):2592-2598.

32. Brausi M, Jones WG, Fossa SD, et al. High dose epirubicin is effective in measurable metastatic prostate cancer: a phase II study of the EORTC Genitourinary Group. Eur J Cancer. 1995;31A(10):1622-1626.

33. Petrioli R, Paolelli L, Francini E, et al. Weekly docetaxel and epirubicin in treatment of advanced hormone-refractory prostate cancer. Urology. 2007;69(1):142-146.

34. Schwartz GG, Oeler TA, Uskokovic MR, et al. Human prostate cancer cells: Inhibition of proliferation by vitamin D analogs. Anticancer Res. 1994;14(3A): 1077-1081.

35. Beer TM, Ryan CW, Venner PM, et al. Double-blinded randomized study of high dose calcitriol plus docetaxel compared with placebo plus docetaxel in androgen-independent prostate cancer: a report from the ASCENT investigators. J Clin Oncol. 2007;25(6):669-674.

36. Chao DT, Korsmeyer SJ. BCL-2 FAMILY: Regulators of cell death. Ann Rev Immunol. 1998;16(1):395-419.

37. Tolcher AW, Kuhn J, Schwartz G, et al. A phase II, pharmacokinetic, and biological correlative study of oblimersen sodium and docetaxel in patients with hormone refractory prostate cancer. Clin Cancer Res. 2005;11(10):3854-3861.

38. Sternberg CN, Dumez H, Van Poppel H, et al. Docetaxel plus oblimersen sodium (Bcl-2 antisense oligonucleotide): an EORTC multicenter, randomized phase II study in patients with castration-resistant prostate cancer. Ann Oncol. 2009;20(7):1264-1269.
39. Miyake H, Hara I, Kamidono S, et al. Resistance to cytotoxic chemotherapy-induced apoptosis in human prostate cancer cells is associated with intracellular clusterin expression. Oncol Rep. 2003; 10(2):469-473.

40. Chi KN, Eisenhauer E, Fazli L, et al. A phase I pharmacokinetic and pharmacodynamic study of OGX-011, a 2'-methoxyethyl antisense oligonucleotide to clusterin, in patients with localized prostate cancer. J Natl Cancer Inst. 2005;97(17)1287-1296.

41. Mani S, Macapinlace M Jr, Goel S, et al. The clinical development of new mitotic inhibitors that stabilize the microtubule. Anticancer Drug. 2004; 15(6):553-558.

42. Galsky MD, Small EJ, Oh WK, et al. Multi-institutional randomized phase II trial of the epothilone B analog ixabepilone (BMS-247550) with or without estramustine phosphate in patients with progressive castrate metastatic prostate cancer. J Clin Oncol. 2005;23(7):1439-1446.

43. Hussain M, Tangen C, Lara P, et al. Ixabepilone (epothilone B analogue BMS-247550) is active in chemotherapy-naive patients with hormonerefractory prostate cancer: a Southwest Oncology Group trial S0111. J Clin Oncol. 2005;23(34):8724-8729.

44. Rosenberg JE, Kelly WK, Michaelson MD, et al. A randomized phase II study of ixabepilone (Ix) or mitoxantrone and prednisone (MP) in patients with taxane (T)-resistant hormone refractory prostate cancer (HRPC). J Clin Oncol. 2005;23(16s): Abstract \# 4566.

45. Chi KN, Beardsley EK, Venner PM, et al. A phase II study of patupilone in patients with metastatic hormone refractory prostate cancer (HRPC) who have progressed after docetaxel. J Clin Oncol. 2008;26(15s): Abstract \# 5166.

46. Jordan MA, Kamath K, Manna T, et al. The primary antimitotic mechanism of action of the synthetic halichondrin E7389 is suppression of microtubule growth. Mol Cancer Ther. 2005;4(7):1086-1095.

47. de Bono JS, Maroto P, Calvo E, et al. Phase II study of eribulin mesylate (E7389) in patients (patients) with metastatic castrationresistant prostate cancer (CRPC) stratified by prior taxane therapy. Proc Am Soc Clin Oncol. (2009 Genitourinary Cancer Symposium); Abstract \# 166.

48. Nam S, Kim D, Cheng JQ, et al. Action of the Src family kinase inhibitor, dasatinib (BMS-354825), on human prostate cancer cells. Cancer Res. 2005;65:9185-9189.

49. Edwards J, Krishna NS, Witton CJ, et al. Gene amplifications associated with the development of hormone-resistant prostate cancer. Clin Cancer Res. 2003;9(14):5271-5281.

50. Tatarov O, Mitchell TJ, Seywright M, et al. SRC family kinase activity is up-regulated in hormone-refractory prostate cancer. Clin Cancer Res. 2009;15(10):3540-3549.

51. Koreckij T, Nguyen H, Brown LG, et al. Dasatinib inhibits the growth of prostate cancer in bone and provides additional protection from osteolysis. Br J Cancer. 2009;101:263-68.

52. Yu EY, Wilding G, Posadas E, et al. Phase II study of dasatinib in patients with metastatic castration-resistant prostate cancer. Clin Cancer Res. 2009;15(23):OF1-8.

53. Higano C, Saad F, Somer B, et al. A phase III trial of GVAX immunotherapy for prostate cancer vs docetaxel plus prednisone in asymptomatic, castration-resistant prostate cancer (CRPC). Proc Am Soc Clin Oncol. (2009 Genitourinary Cancer Symposium); Abstract \# LBA150.

54. Small E, Demkov T, Gerritsen WR, et al. A phase III trial of GVAX immunotherapy for prostate cancer in combination with docetaxel vs docetaxel plus prednisone in symptomatic, castration-resistant prostate cancer (CRPC). Proc Am Soc Clin Oncol. (2009 Genitourinary Cancer Symposium); Abstract \# 7.

55. Tannock IF, de Wit R, Berry WR, et al. Chemotherapy with mitoxantrone plus prednisone or prednisone alone for symptomatic hormoneresistant prostate cancer: a Canadian randomized trial with palliative end points. J Clin Oncol. 1996;14(6):1756-1764.

56. Kantoff PW, Halabi S, Conaway M, et al. Hydrocortisone with or without mitoxantrone in men with hormone-refractory prostate cancer: results of the cancer and leukemia group B 9182 study. J Clin Oncol. 1999;17(8):2506-2513. 
57. Berry W, Dakhil S, Modiano M, et al. Phase III study of mitoxantrone plus low dose prednisone vs low dose prednisone alone in patients with asymptomatic hormone refractory prostate cancer. J Urol. 2002;168(6):2439-2443.

58. Garmey EG, Sartor O, Halabi S, et al. Second-line chemotherapy for advanced hormone-refractory prostate cancer. Clin Adv Hematol Oncol. 2008;6(2):118-122, 127-132.

59. George DJ, Halabi S, Shepard TF, et al. Prognostic significance of plasma vascular endothelial growth factor levels in patients with hormone-refractory prostate cancer treated on Cancer and Leukemia Group B 9480. Clin Cancer Res. 2001;7(7):1932-1936.

60. Di Lorenzo G, Figg WD, Fossa SD, et al. Combination of bevacizumab and docetaxel in docetaxel-pretreated hormone-refractory prostate cancer: A phase 2 study. Eur Urol. 2008;54(5):1089-1096.

61. Dahut WL, Scripture C, Posadas E, et al. A phase II clinical trial of sorafenib in androgen-independent prostate cancer. Clin Cancer Res. 2008;4(1):209-214.

62. Latif T, Wood L, Connell C, et al. Phase II study of oral bis (aceto) ammine dichloro (cyclohexamine) platinum (IV) (JM-216, BMS182751) given daily x 5 in hormone refractory prostate cancer (HRPC). Invest New Drugs. 2005;23(1):79-84.

63. Sternberg CN, Whelan P, Hetherington J, et al. Phase III trial of satraplatin, an oral platinum plus prednisone vs prednisone alone in patients with hormone-refractory prostate cancer. Oncology. 2005;68(1):2-9.

64. Sartor AO, Petrylak DP, Witjes JA, et al. Satraplatin in patients with advanced hormone-refractory prostate cancer (HRPC): Overall survival (OS) results from the phase III satraplatin and prednisone against refractory cancer (SPARC) trial. J Clin Oncol. 2008;26(15s): Abstract \#5003.
65. Beardsley EK, Saad F, Eigl B, et al. A phase II study of patupilone in patients (patients) with metastatic castration-resistant prostate cancer (CRPC) who have progressed after docetaxel. J Clin Oncol. 2009;27(15s): Abstract \# 5139.

66. Rosenberg JE, Weinberg V, Kelly KW, et al. Activity of second-line chemotherapy in docetaxel-refractory hormone-refractory prostate cancer patients: randomized phase 2 study of ixabepilone or mitoxantrone and prednisone. Cancer. 2007;110(3):556-563.

67. Thakkar SG, Choueiri TK, Garcia JA. Endothelin receptor antagonists: Rationale, clinical development, and role in prostate cancer therapeutics. Curr Oncol Rep. 2006;8(2):108-113.

68. Nelson JB, Hedican SP, George DJ, et al. Identification of endothelin-1 in the pathophysiology of metastatic adenocarcinoma of the prostate. Nature Med. 1995;1(9):944-949.

69. Carducci MA, Saad F, Abrahamsson P, et al. A phase 3 randomized controlled trial of the efficacy and safety of atrasentan in men with metastatic hormone-refractory prostate cancer. Cancer. 2007;110: 1959-1966.

70. Attard G, Belldegrun AS, de Bono JS. Selective blockade of androgenic steroid synthesis by novel lyase inhibitors as a therapeutic strategy for treating metastatic prostate cancer. BJU Int. 2005;96(9):1241-1246.

71. Tran C, Ouk S, Clegg NJ, et al. Development of a second-generation antiandrogen for treatment of advanced prostate cancer. Science. 2009;324(5928):787-790.

72. Small EJ, Schellhammer PF, Higano CS, et al. Placebo-controlled phase III trial of immunologic therapy with sipuleucel-T (APC8015) in patients with metastatic, asymptomatic hormone refractory prostate cancer. J Clin Oncol. 2006;24(19):3089-3094.
OncoTargets and Therapy

\section{Publish your work in this journal}

OncoTargets and Therapy is an international, peer-reviewed, open access journal focusing on the pathological basis of all cancers, potential targets for therapy and treatment protocols employed to improve the management of cancer patients. The journal also focuses on the impact of management programs and new therapeutic agents and protocols on

\section{Dovepress}

patient perspectives such as quality of life, adherence and satisfaction. The manuscript management system is completely online and includes a very quick and fair peer-review system, which is all easy to use. Visit http://www.dovepress.com/testimonials.php to read real quotes from published authors. 